Supplement of The Cryosphere, 14, 3269-3286, 2020

https://doi.org/10.5194/tc-14-3269-2020-supplement

(C) Author(s) 2020. This work is distributed under

the Creative Commons Attribution 4.0 License.

(c) (1)

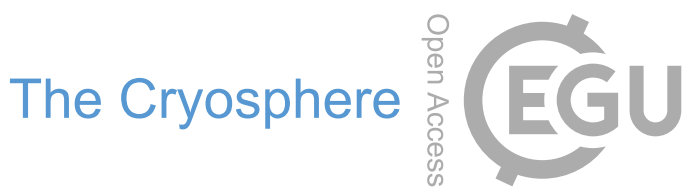

Supplement of

\title{
Monitoring the seasonal changes of an englacial conduit network using repeated ground-penetrating radar measurements
}

Gregory Church et al.

Correspondence to: Gregory Church (church@ vaw.baug.ethz.ch)

The copyright of individual parts of the supplement might differ from the CC BY 4.0 License. 


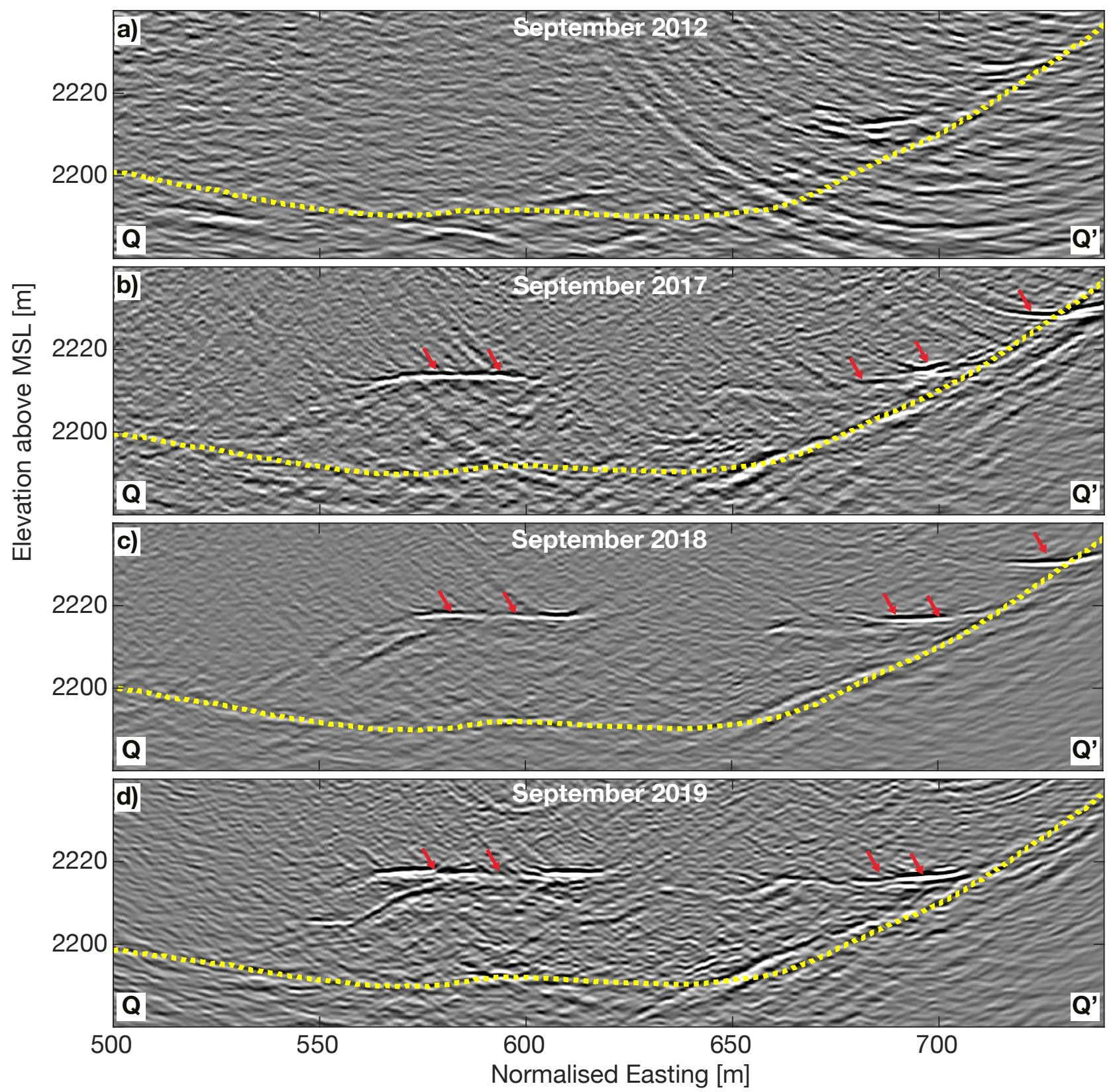

Figure S1. GPR imaging results from a repeated profile over a single line after migration from 2012 until 2019 showing zoomed in area of englacial conduit reflection. The yellow line represents the ice-bedrock interface and the red arrows represent the englacial conduit network reflection appearing from summer 2017. 

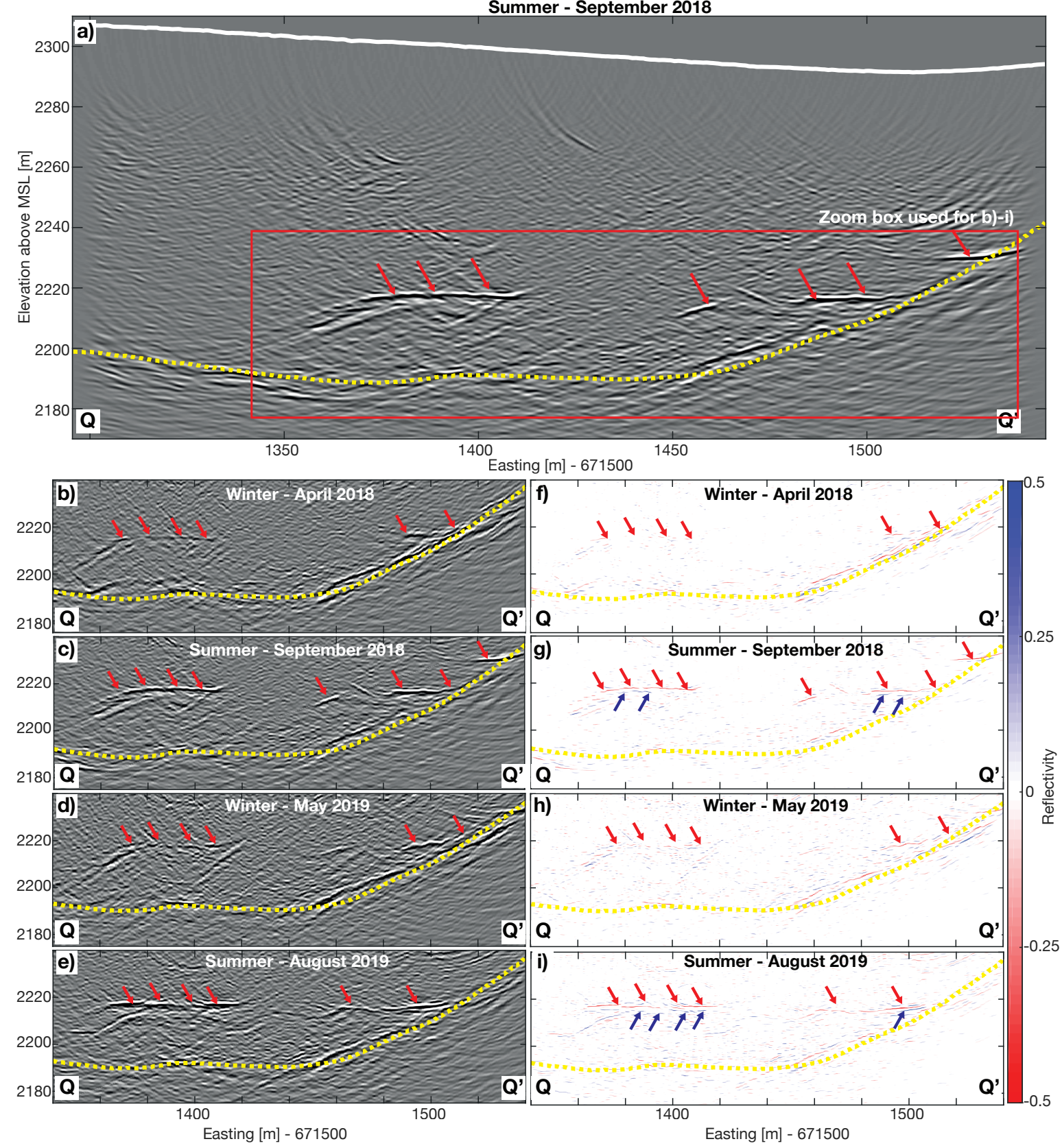

Figure S2. a) GPR imaging results over a single repeated GPR profile (Q-Q' in Fig. 1) in 2018. The yellow line represents the ice-bedrock interface, white line represents the glacier surface, and the red box is the zoom box for GPR imaging and reflectivity results b)-i). b)-e) are seasonal GPR imaging results and f)-i) are the seasonal GPR reflectivity results from b)-e). The red arrows represent the top of the englacial conduit network and the blue arrows represent the bottom of the englacial conduit network ( $g$ \& i). 

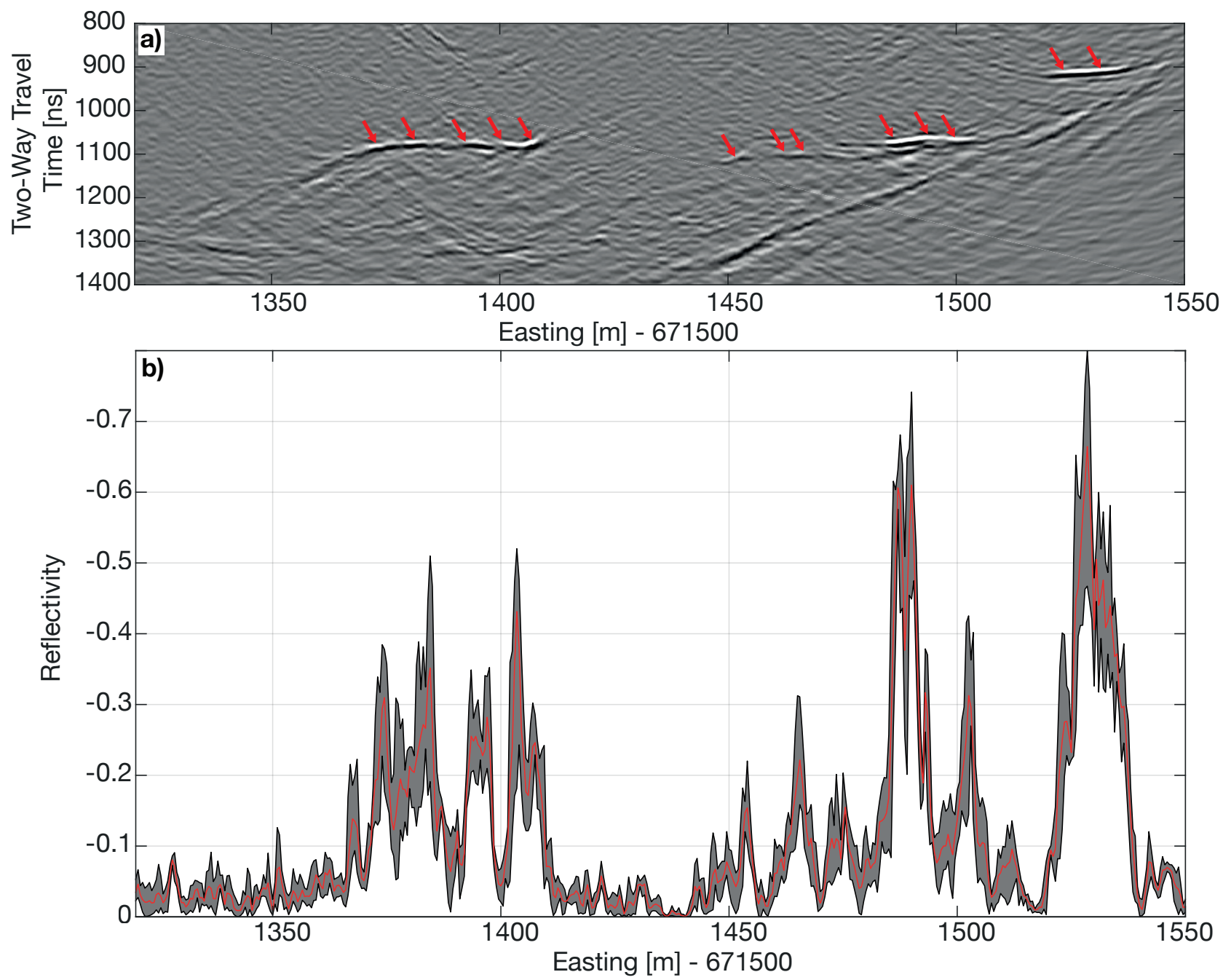

Figure S3. Uncertainty results from repeated GPR profiles undertaken in July 2018. a) GPR imaging result for repeated profile. b) Apparent reflectivity extracted from the GPR field data. The grey filled area represents the minimum and maximum reflectivity range from the four repeated profiles. The red line is the mean of the four profiles. 


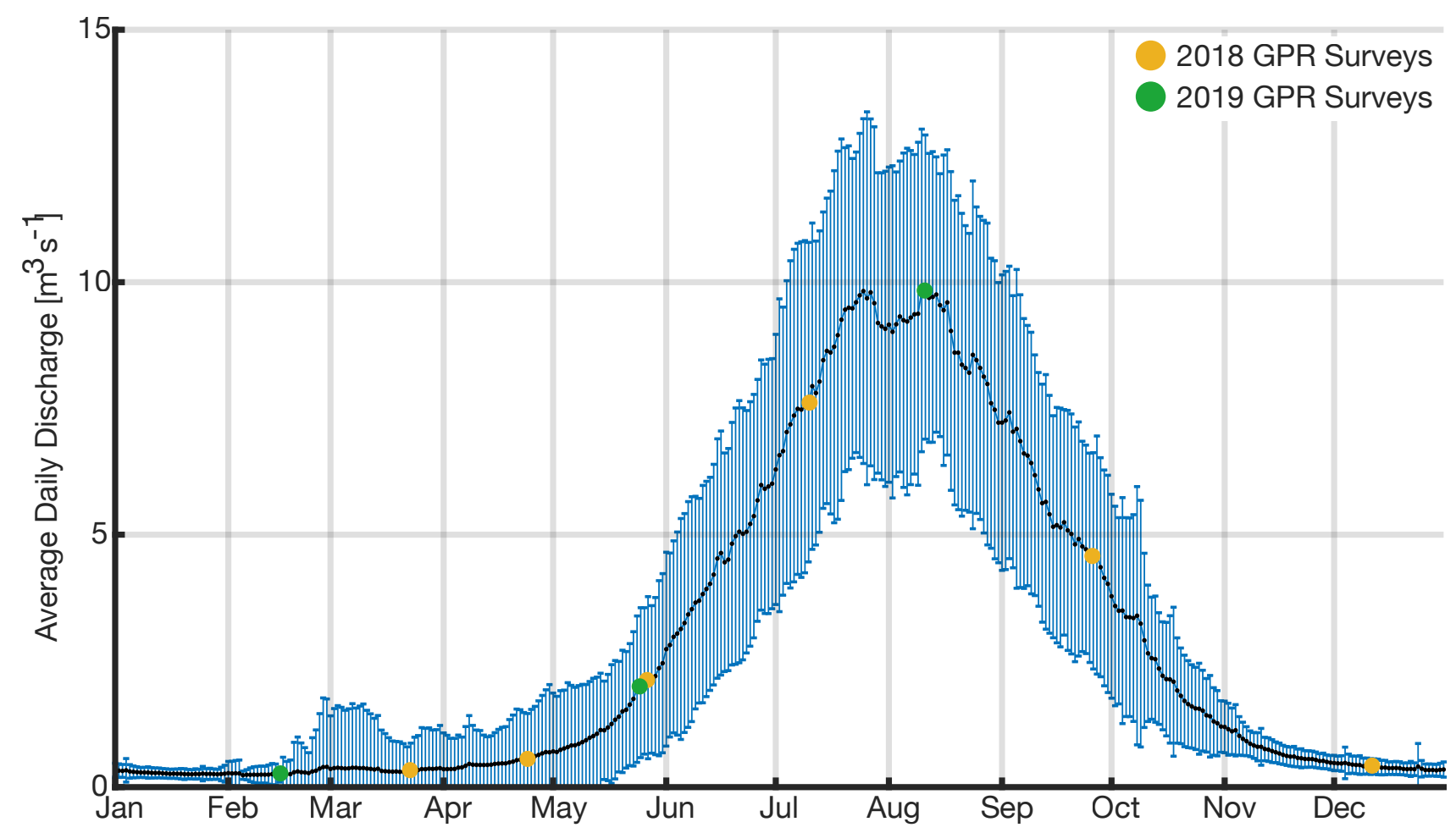

Figure S4. Average daily discharge measured in Gletsch ( $2 \mathrm{~km}$ downstream of Rhonegletscher) between 1957 and 2017. The error bars represent two standard deviations. The yellow and green dots represent the GPR survey dates for 2018 and 2019 respectively. 

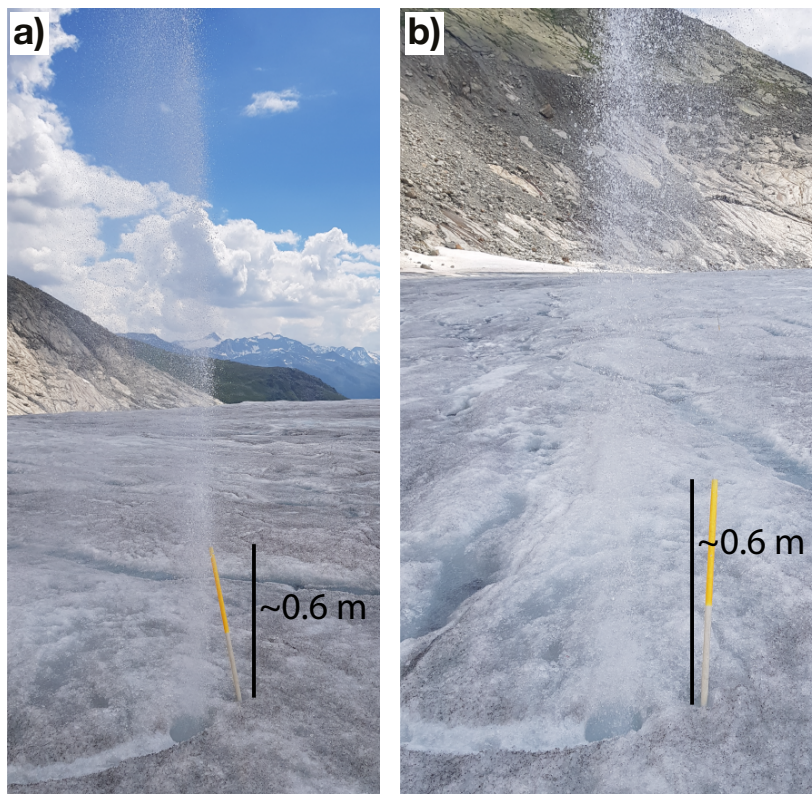

Figure S5. Borehole surface observations taken on 24th July 2018 showing water being forcibly spouted from the borehole head upto a height of approximately $4 \mathrm{~m}$. Such observations were also recorded on 3rd August 2018. 